\title{
Numerical analysis of the flow rig for UWS spray examination in exhaust system- relevant conditions
}

ARTICLE INFO

Received: 16 July 2021

Revised: 22 July 2021

Accepted: 10 August 2021

Available online: 19 August 2021

In the present study, a flow rig with optical access intended for spray investigations in exhaust systemrelevant conditions was analysed in terms of flow and temperature in the spray area using numerical simulations. The operation of the rig was examined for a wide range of exhaust mass flow rates, temperatures and various forms of UWS (urea-water solution) spray plumes. The locations of the injector and thermocouple were verified. Both conventional and flash-boiling injections were considered to assess the effect of the interaction of sprays with a gas flow. The results showed a highly uniform flow in the visualisation area, with only minor fluctuations near the walls. A similar observation was carried out for the temperature distribution. It was found that the extreme operating conditions caused substantial deformations of the spray plumes. However, the selected injector location allowed us to properly observe the spray formation regardless of the flow conditions. The study showed that the examined test rig enabled reliable spray investigations for a wide range of operating points.

Key words: CFD, spray, injection, crossflow, flow rig

This is an open access article under the CC BY license (http://creativecommons.org/licenses/BY/4.0/)

\section{Introduction}

Selective catalytic reduction is one of the most efficient $\mathrm{NO}_{\mathrm{x}}$ reduction methods. It requires a UWS injection responsible for concurrent ammonia generation, resulting in chemical reactions leading to $\mathrm{NO}_{\mathrm{x}}$ conversion into nonhazardous compounds. The working conditions of SCR systems are very changeable. Although challenging, the reconstruction of a broad working range in laboratory conditions can be obtained by specially designed flow rigs [2]. These devices become a crucial enhancement in SCR development, allowing for continuous, long-term tests in precisely controlled conditions without the necessity for actual engine applications. The flow rigs can be designed also for UWS spray visualisation [8, 9, 12, 13]. Spray investigations in flow conditions are necessary to validate numerical models and for evaluation of the consequences of droplet-flow-related phenomena. Nonetheless, the attainment of highly uniform velocity distribution and temperature in the spray-affected zone is required for proper interpretations of the droplet-flow interactions.

One of the crucial spray behaviours to be investigated in engine-related crossflow conditions is, among others, the spray's drift caused by interactions of droplets with the flow. This phenomenon depends on the unintentional move of the droplets, when their trajectories are shifted by the gas flow. The drift is mainly influenced by gas and droplet momentum and the droplet's volume-to-surface ratio; hence, droplet sizing and initial injection velocity play a significant role [10-12, 14, 17, 19]. Moreover, various types of spray clouds, including those formed under flashboiling conditions, result in diverse effects of interactions with the gas flow. The flash-boiling injection is particularly advantageous as it provides a high level of urea decomposition and uniform ammonia distribution [4, 5]. However, those sprays are characterised by significantly smaller droplets, lower velocity and increased angles, and therefore are highly exposed to the drift $[3,7,10,11,13,14,17-19]$.
Even though UWS sprays occur along with the crossflow, they are usually examined in quiescent environments. Macro- and microscopic optical spray measurements in crossflow conditions were presented by Payri et al. [12]. The spray shape was barely altered by the change in the flow temperature (up to $350^{\circ} \mathrm{C}$ ). However, the gas flow temperature rise caused the enhancement of droplet evaporation, which was observed at an increased distance from the injector nozzle. Another work of Payri et al. [13] comprised an experimental survey of UWS droplet diameter distribution in an engine-exhaust corresponding environment. A single plume was observed, even though the threehole injector was applied at an operating pressure ranging from 4 to 8 bar. The maximum flow temperature reached $350^{\circ} \mathrm{C}$; while the gas mass flow rate was constant and equal to $40 \mathrm{~kg} / \mathrm{h}$. The authors pointed out that observations close to the nozzle are out of the particular area of interest as there is no significant effect from the crossflow visible in this region. A rise in the flow velocity and temperature enhanced the spray penetration in the longitudinal and transverse directions. Payri et al. [14] examined the UWS spray atomisation at a flow temperature of $350^{\circ} \mathrm{C}$ in the test rig by numerical methods and experimental validation. The spray formation was highly influenced by the droplet's momentum. They reported intensive deflection of tiny droplets that were blown by the gas flow. This phenomenon consequently introduced a particular form of size-based droplet segregation. The higher the gas mass flow rate was imposed, the higher the droplet diameter prevailed at the initial observation point, placed downstream to the injection axis. Additionally, the secondary breakup was not induced by gas-droplet interactions. However, a reduction in splash effects due to the crossflow was advantageous in terms of optical measurements, since the number of droplets entrained back into the flow was lower. Spiteri et al. [17] observed a substantial influence from the gas flow on small droplets which were accelerated or decelerated, depending 
on the gas velocity. However, the impact of the crossflow on the propagation velocity of the whole spray or of the initial spray angle was low. Surprisingly, the transverse spray velocity was not affected by the crossflow. Moreover, vortices were observed behind the spray, which were developed by the spray itself (particularly in the region of the liquid jet) or by bifurcation and blooming. The high impact of the passing exhaust gas on the spray formation was also reported in another research study by Spiteri et al. [18], in which inclined air-assisted and pressure-atomised injectors were used in the flow rig. Likewise, the smaller droplets were influenced by the gas flow, which in the case of a velocity lower than the droplet velocity, caused their deceleration. On the contrary, large droplets tended to remain close to the spray axis. The air-assisted spray cloud was so intensely deformed by the gas flow rate of $300 \mathrm{~kg} / \mathrm{h}$ that collisions of droplets with the bottom walls were avoided, despite the low $80 \mathrm{~mm}$ height of the duct. The maximum flow temperature in the above two studies was $400^{\circ} \mathrm{C}$. A similar dependence on droplet movements due to the crossflow was observed experimentally by Liao et al. [7]. The interaction between the flow and the spray was particularly intense in the case of air-assisted injector application. The flow rig was aimed at optical spray measurements and the similar results were also presented by Schmidt et al. [16]. The rig enabled relevant tests for a diesel engine in crossflow conditions with a mass flow rate up to $1000 \mathrm{~m}^{3} / \mathrm{h}$ and a temperature of $800 \mathrm{~K}$. The turbulent flow in the spray section occurred. Difficulties in optical spray measurements due to the high gas temperature were reported by Lieber et al. [8] and concerned Schlieren effects as well as stigmatism. Their experimental measurements were conducted in flow conditions at temperatures of 293 and $773 \mathrm{~K}$ and comprised an axially aligned air-assisted injector. By watercooling the part providing the optical access and the astigmatism correction plate, it resulted in significant improvement of the quality of the images.

Nishad et al. [10] performed large-eddy simulations of inclined spray injections in the flow channel at the maximum gas temperature of $400^{\circ} \mathrm{C}$ and mass flow rate up to $400 \mathrm{~kg} / \mathrm{h}$. The spray was modelled by the EulerianLagrangian method and primary and secondary breakup models were also considered. A negligible influence from the secondary breakup model was reported, contrary to the collision model. Large droplets followed the spray centreline, while the smaller droplets were moved by the flow. Drag resulting from the crossflow was responsible for the spray core disintegration, and the introduction of relatively small droplets shifted from the spray axis. Varna et al. [19] presented a numerical and experimental survey on inclined UWS sprays in a crossflow test rig. The authors determined the influence of individual models. Analogously to the most of the previously mentioned research, they observed a spray drift caused by the presence of the crossflow. Wall-jet vortices were distinguished at the bottom walls, which were responsible for the entrainment of small droplets. The spray core contributed to the development of the vortices, especially when the gas flow rate was relatively low, preventing the tiny droplets from moving further downstream. Reduction in spray width, droplet's dispersion and overall drop- let's number density, along with a rise in gas crossflow, was reported in another experimental and numerical analysis by Varna et al. [20]. A substantial double-vortex formation was observed, but surprisingly, an increase in the gas mass flow rate from 100 to $400 \mathrm{~kg} / \mathrm{h}$ led to its extinction. Nocivelli et al. [11] observed that the spray core composed of larger droplets was slightly affected by the crossflow (contrary to the smaller droplets), and pointed out the importance of the definition of droplet parcels in the case of the Lagrangian spray modelling approach. Another factor required for proper spray measurements is a stable flow. This was indicated by Aditya Wardana et al. [1] with a numerical simulation of UWS injection into the flow channel. It was required that 20 seconds of the flow was simulated until the steady conditions were reached. If the injection was started before this state, a deposition of ureaby-products might have occurred. The evaporation of water from the UWS was also restricted.

There is still an insufficient amount of research concerning UWS sprays in crossflow conditions, and the importance of the uniform velocity and temperature distribution in the spray area is not sufficiently addressed. In order to bridge the gaps, the present work shows the numerical analysis of a flow rig that enables spray measurements in high-crossflow and high-temperature environments that reflect the actual wide range of a diesel engine's exhaust conditions. The results will be used for the rig's physical development; however, that is out of the scope of the current work.

The aim of the study is a numerical analysis of the flow rig intended for spray investigations and verification of its usability. This involves the determination of the influence of extreme exhaust crossflow conditions on spray measurements, including a broad range of mass flow ratios and high flow temperatures.

\section{Model}

In order to investigate the phenomena occurring during the injection of a UWS in the exhaust system, it was decided to design a flow section that would allow observations and analysis of the injection process in the hightemperature and high-crossflow conditions. The conceptual assumption of the device was to reproduce the conditions in an exhaust system equipped with an SCR catalyst.

To minimise the influence of the turbulences on the injected spray and improve the spray analysis quality, the exhaust system's model had to be simplified. For the purposes of the research, it was decided to use a straight flow channel with adjustable mass-flow rate and the temperature of the air. The flow rig was equipped with an injector mounted perpendicularly to the flow direction. The main goal of this study was the numerical verification of the flow rig concept, with particular emphasis on the uniformity of the gas flow in the injection area.

\subsection{Model characteristics}

The design of the flow rig discussed in this article consisted of a flow channel, an injector socket and windows providing optical access for the observation of the injected sprays. The device had the form of a tube with an initial 
Table 1. Material data used for CFD calculations

\begin{tabular}{|l|c|c|c|}
\hline Material & Density $\left[\mathrm{kg} / \mathrm{m}^{3}\right]$ & Thermal conductivity $[\mathrm{W} / \mathrm{m} \cdot \mathrm{K}]$ & Specific heat $[\mathrm{J} / \mathrm{kg} \cdot \mathrm{K}]$ \\
\hline Stainless Steel & 7900 & 15 & 500 \\
\hline Quartz & 2200 & 1.3 & 650 \\
\hline
\end{tabular}

circular cross section and a diameter of $100 \mathrm{~mm}$, smoothly passing into a square cross section with a side of $140 \mathrm{~mm}$ in the major part of the flow rig. The injector was mounted via the injector socket on the upper wall of the device. In order to minimise the influence of the boundary layer on the injection area, the injector socket was recessed into the flow. The injector seat and the channel walls were to be made of stainless steel. Optical access was provided by windows made of quartz. The two main windows were located on the sidewalls of the flow section. They enabled observation and analysis of the UWS injection. The other two smaller windows were designed on the top and bottom of the device. In order to control the flow temperature, the need to install a thermocouple located on the bottom wall of the flow rig, in the flow symmetry axis, was anticipated at a distance of $200 \mathrm{~mm}$ from the injector axis plane. The flow rig is presented in Fig. 1.

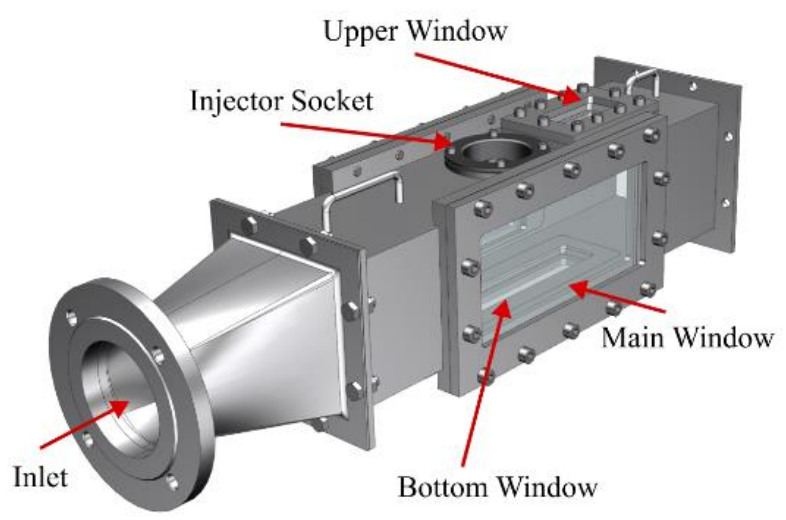

Fig. 1. Conceptual model of the considered flow rig

A variable cross section close to the system's inlet and the configuration of the windows might cause flow disturbances. The presence of the thermocouple and the injector socket might also affect the flow uniformity. During numerical simulations, the emphasis was placed on verifying the velocity and temperature uniformity of the flow in the spray zone. The correctness of the thermocouple's placement and the windows were checked.

The initial gas flow could be provided in an actual device, for example, by the system discussed in [2]. The occurrence of initial flow disturbances would have an additional impact on the irregularity in the flow rig. For simulation purposes, this factor was omitted, and the calculations were conducted with the assumption of an homogeneous flow at the inlet. This simplification made it possible to exclude the influence of a particular gas supply unit.

\subsection{CFD analysis}

The numerical simulations of the model were carried out using AVL Fire software. The Reynolds-averaged Navier-Stokes (RANS) approach was used. Based on the geo- metrical model of the flow rig, a computational domain was created. The accurately mapped flow area included the injector socket, recesses at the optical access windows and the thermocouple. The model was discretised with polyhedral mesh elements. The base cell size was set to $5 \mathrm{~mm}$ and $3 \mathrm{~mm}$ on the surface. The computational mesh is shown in Fig. 2.

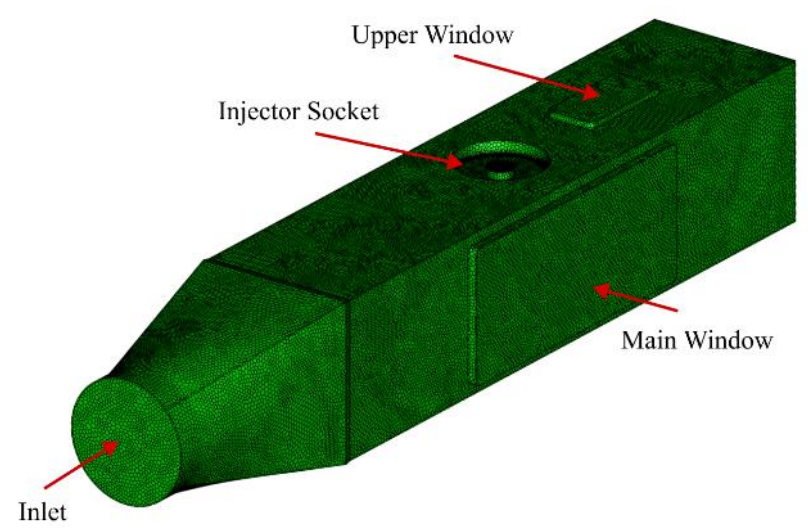

Fig. 2. The mesh of the computational domain of the considered flow rig

To ensure a realistic temperature distribution inside the system and at its walls, a radial heat exchange model implemented in the AVL Fire software was used. In areas where the model assumes some overlapping of materials (Fig 3), a simplification was required. However, such regions constituted about $6.3 \%$ of the outer rig surface, and therefore, the simplification was presumed to have no particular influence on the final data. Since the simulation of temperature distribution inside the walls was not the subject of the research, the applied heat transfer model allowed us to obtain satisfactory results. The material properties used for calculations are given in Table 1.

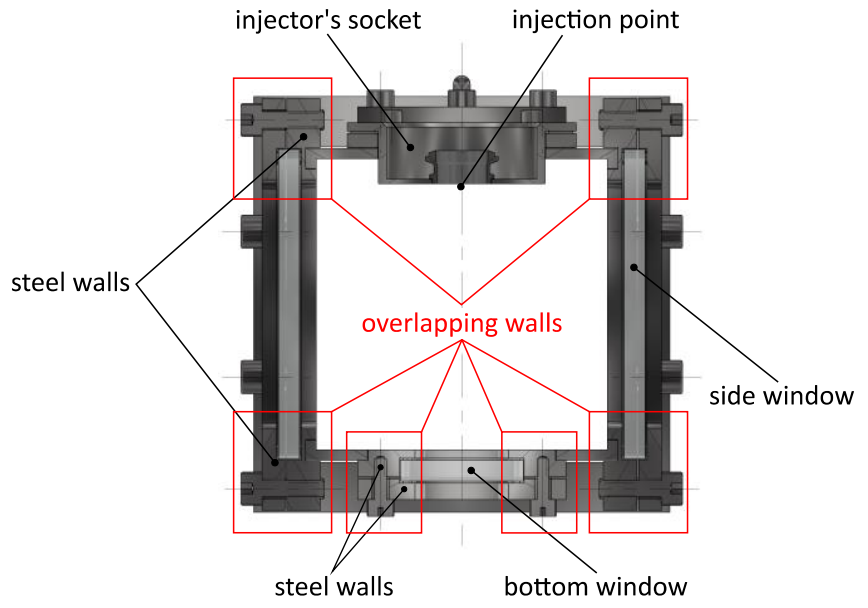

Fig. 3. The cross section through the injection plane. The areas of overlapping materials are marked by red rectangles 
Numerical analysis of the flow rig for UWS spray examination in exhaust system-relevant conditions

Table 2. UWS dosing and injector opening times for considered operating points

\begin{tabular}{|c|c|c|c|c|c|}
\hline & & \multicolumn{2}{|c|}{ UWS temperature $83^{\circ} \mathrm{C}$} & \multicolumn{2}{|c|}{ UWS temperature $143^{\circ} \mathrm{C}$} \\
\hline $\begin{array}{l}\text { Mass flow rate } \\
{[\mathrm{kg} / \mathrm{h}]}\end{array}$ & $\begin{array}{l}\text { UWS mass flow rate } \\
{[\mathrm{mg} / \mathrm{s}]}\end{array}$ & $\begin{array}{l}\text { UWS portion per } \\
\text { injection } \\
{[\mathrm{mg}]}\end{array}$ & $\begin{array}{l}\text { Opening time } \\
{[\mathrm{ms}]}\end{array}$ & $\begin{array}{c}\text { UWS portion } \\
\text { per injection } \\
{[\mathrm{mg}]}\end{array}$ & $\begin{array}{l}\text { Opening time } \\
{[\mathrm{ms}]}\end{array}$ \\
\hline 150 & 19.99 & 4.997 & 11.4 & 4.653 & 11.4 \\
\hline 300 & 39.98 & 9.995 & 22.8 & 9.306 & 22.8 \\
\hline 750 & 99.95 & 24.987 & 57.0 & 23.265 & 57.0 \\
\hline
\end{tabular}

The operating conditions were adjusted by changing the mass flow rate and the gas temperature at the inlet. The temperature and mass flow range exceeded the scope of typical exhaust system conditions. Depending on the tested operating point, the air mass flow rate at the inlet to the system ranged from $150 \mathrm{~kg} / \mathrm{h}$ to $750 \mathrm{~kg} / \mathrm{h}$, and the inlet gas temperature ranged from 150 to $750^{\circ} \mathrm{C}$. Those conditions resulted in an average velocity in the injector axis plane from $2.42 \mathrm{~m} / \mathrm{s}$ for the lowest mass flow rate and temperature, up to $29.27 \mathrm{~m} / \mathrm{s}$ for the highest flow rate and temperature values.

In addition to the uniformity of the temperature and velocity distributions, the injection process was also analysed. In order to simulate the droplet injection, a discrete droplet model (DDM) was used. Numerical spray analysis covered the entire range of operating conditions. In the simulations, the injection properties provided by the Bosch 0444025030 two-hole injector dosing the UWS at a pressure of 5 bar were used. The injector nozzles were oriented in a plane perpendicular to the flow direction. The simulations were carried out for two different temperatures of the injected UWS, 83 and $143^{\circ} \mathrm{C}$, respectively. Since the UWS saturation temperature at atmospheric pressure is $103^{\circ} \mathrm{C}$, the temperature of $143^{\circ} \mathrm{C}$ in atmospheric pressure led to the flashboiling phenomenon.

The amount of UWS in each injection depended on the $\mathrm{NO}_{\mathrm{x}}$ concentration. Since the constant value of $150 \mathrm{ppm}$ was used, the mass of UWS per injection was a function of the gas mass flow rate. In the case of the tested injector operating under constant injection pressure, the dosing of the appropriate portion of the liquid was regulated by changing the injector's opening time. The respective values for the flows were calculated and presented in Table 2 .

\section{Results}

The CFD simulations were mainly focused on three aspects: uniformity of gas flow (velocity); homogeneity of temperature distribution; and the injection process's visualisation at various flow conditions and degrees of UWS superheat. The numerical analysis was conducted for a wide range of operating conditions. The results are described in the following paragraphs.

\subsection{Velocity Uniformity}

Uniform flow distribution in the spray dispensing area is essential for proper evaluation of the spray-flow interaction. Therefore, the velocity distribution in the flow rig was analysed.

At the entrance to the flow rig, evenly distributed mass flow was assumed. The velocity fluctuations were influenced by the shape of the channel and the elements disturbing the flow.
Regardless of the mass flow rate, the overall velocity distribution in the tested flow rig remained similar. Two extreme calculation cases were shown in Figs 4 and 5. The flow velocity magnitude in the second case was almost 12 times higher than in the first one. Despite such a significant difference, the flow in both cases was characterised by nearly the same velocity distribution.

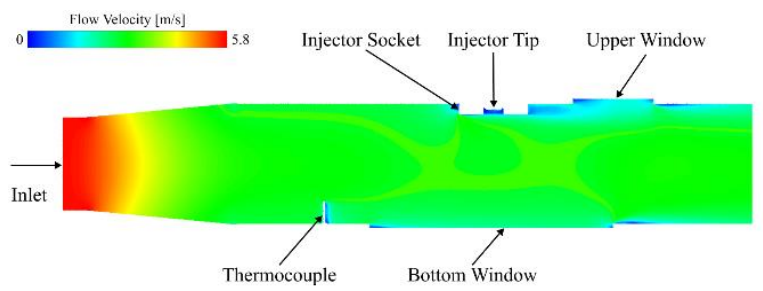

Fig. 4. Velocity distribution at $150^{\circ} \mathrm{C}$ flow temperature and $150 \mathrm{~kg} / \mathrm{h}$ flow rate

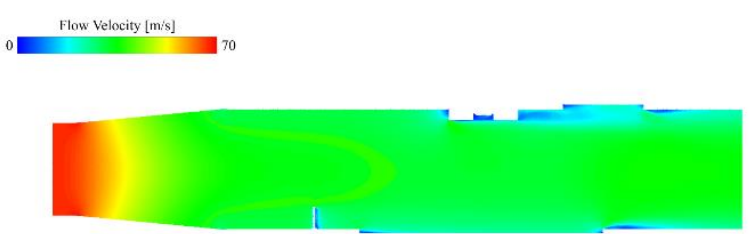

Fig. 5. Velocity distribution at $750^{\circ} \mathrm{C}$ flow temperature and $750 \mathrm{~kg} / \mathrm{h}$ flow rate

The performed calculations showed that regardless of the operating point, the velocity distribution along the flow direction retained a similar character. It was determined by the shape of the channel and the obstacles encountered by the flow. After the initial velocity reduction, due to the expansion of the cross section, the velocity was stabilised. Local drops in velocity resulting from interactions with elements in the flow area were noticeable. The region with the most significant differences in velocity was the injector mounting area. The cylindrical seat in which the injector was placed penetrated the flow, forcing it to flow around on the outer sides. The injector socket was placed into the channel deliberately to move the injector's tip away from the section's wall. This however had an influence on the flow in the neighbouring area.

Further along, there was an area with reduced velocity near the upper window. In this region, the flow was disturbed by the flow around the injector mounting. However, this area was located entirely outside the injection zone.

The thermocouple installed in the flow generated slight flow disturbances. There was an aerodynamic shadow forming behind the temperature sensor. However, it was damped far upstream from the injector's axis and did not affect the uniformity of the velocity field in the injection area. 
An essential aspect of the research was the velocity distribution in the cross section plane in the injector axis (Fig. 6). This section view indicated that the velocity increased around the sidewalls of the injector's seat, while it decreased below its bottom wall. Limited airflow near the injector's tip was also clearly visible. Because of the presence of this low-velocity zone, the injected UWS was exposed to a strong crossflow after travelling a distance of approximately $6 \mathrm{~mm}$. The influence of the windows on the velocity field's uniformity in the injector axis plane was negligible. Due to the relatively long distance between the windows and the spray area, the disturbances did not affect the injection area.

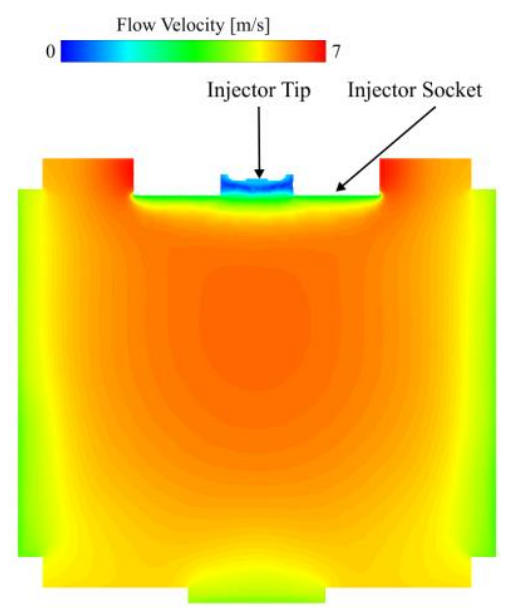

Fig. 6. Velocity distribution at $750^{\circ} \mathrm{C}$ flow temperature and $150 \mathrm{~kg} / \mathrm{h}$ flow rate in the injection's plane

The occurrence of increased turbulence around the injector seat was confirmed by analysing velocity vectors on the plane of injection shown in Fig. 7. However, almost no turbulence was observed in the injection zone.

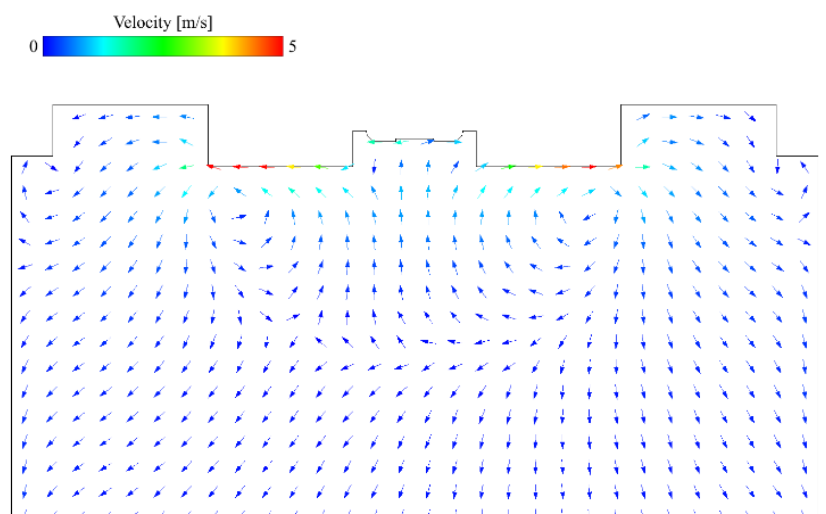

Fig. 7. Velocity vectors orthogonal to the flow direction at $750{ }^{\circ} \mathrm{C}$ flow temperature and $600 \mathrm{~kg} / \mathrm{h}$ of flow rate

To quantitatively assess the results of the flow velocity uniformity, the velocity uniformity index defined by Eq. (1) was considered in reference to the cross-sectional plane in the injector axis:

$$
\mathrm{UI}_{\mathrm{vel}}=1-\frac{\sum\left|\mathrm{v}_{\mathrm{i}}-\mathrm{v}_{\mathrm{avg}}\right| \cdot \mathrm{A}_{\mathrm{i}}}{2 \cdot \mathrm{v}_{\mathrm{avg}} \cdot \sum \mathrm{A}_{\mathrm{i}}}
$$

where: $A_{i}$ was a surface area of a given mesh element; $\mathrm{v}_{\mathrm{avg}}$ was the average velocity value; and $\mathrm{v}_{\mathrm{i}}$ was the actual velocity in the corresponding mesh element.

The homogeneity of the flow under this method was almost equal for all of the considered cases and, depending on the operational conditions, had values between 95.9 and $96.2 \%$. The values of the velocity uniformity index are presented in Figs 8 and 9.

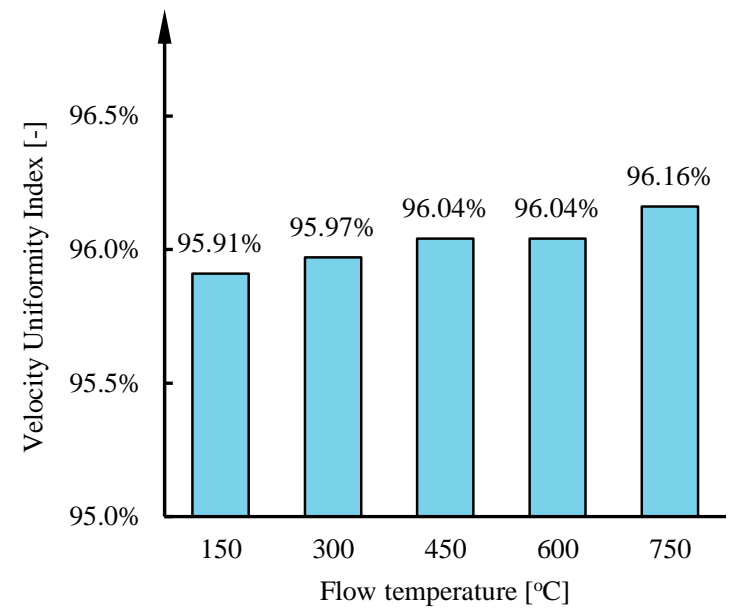

Fig. 8. Velocity uniformity index for a mass flow rate of $750 \mathrm{~kg} / \mathrm{h}$

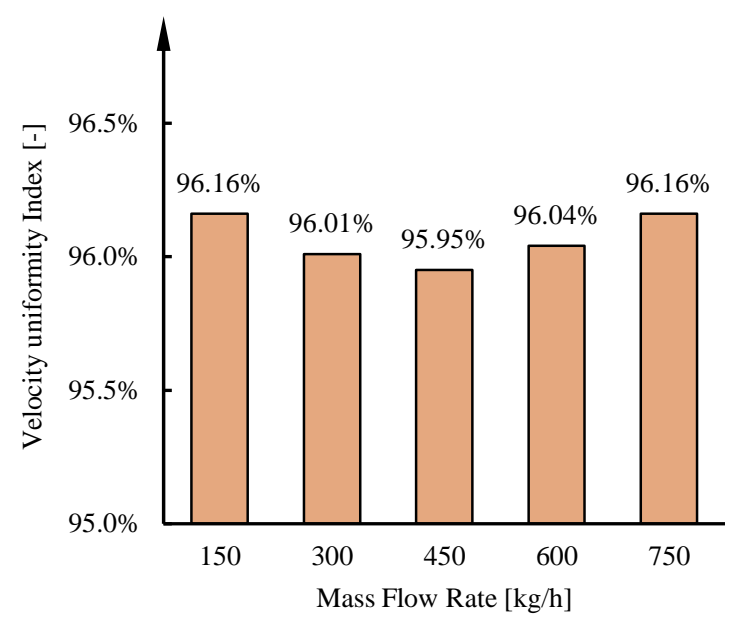

Fig. 9. Velocity uniformity index for the flow temperature of $750^{\circ} \mathrm{C}$

The main factor affecting the uniformity of the flow was the particular mounting of the studied injector. Using a different design could cause a further increase in the already high values of the velocity uniformity index.

\subsection{Temperature distribution}

To diminish the influence of the system boundaries on the spray formation process at high temperatures, it was necessary to provide a uniform temperature in the injection area. Therefore, simulations were carried out to determine the temperature distribution in the flow section for the entire range of operating conditions.

The temperature distribution, depicted in Figs 10 and 11 , turned out to have a similar nature for all the examined operating points. However, depending on the conditions, 
the areas with considerable temperature drops changed significantly. In the case of high temperature and lowvelocity flows, there was a more significant drop in temperature. Those areas of lowered temperature were located where the flow was disturbed by the injector socket and in the vicinity of the walls of the flow section. The temperature distribution for a flow temperature of $750^{\circ} \mathrm{C}$ and a mass flow rate of $150 \mathrm{~kg} / \mathrm{h}$ and $750 \mathrm{~kg} / \mathrm{h}$ are presented in Figs 10 and 11, respectively. In both cases, it was possible to observe reduced-temperature zones behind the injector seat and behind the lower window. In the case of a lower mass flow rate, the temperature in those places reached much lower values.
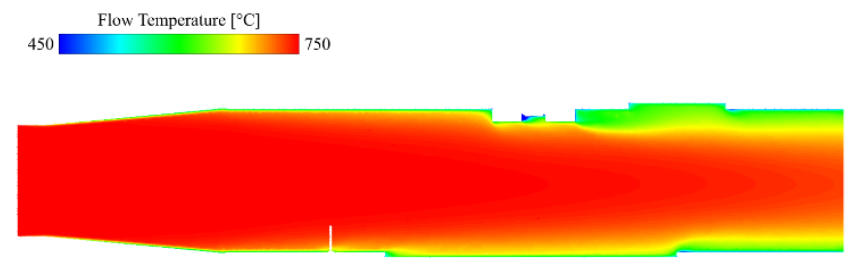

Fig. 10. Temperature distribution at $750^{\circ} \mathrm{C}$ flow temperature and $150 \mathrm{~kg} / \mathrm{h}$ flow rate

Flow Temperature $\left[{ }^{\circ} \mathrm{C}\right]$
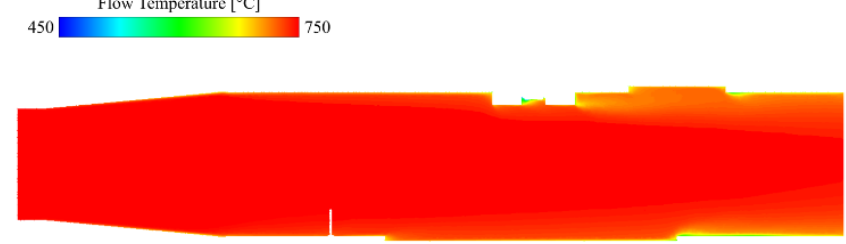

Fig. 11. Temperature distribution at $750^{\circ} \mathrm{C}$ flow temperature and $750 \mathrm{~kg} / \mathrm{h}$ flow rate

Depending on the flow conditions, the thickness of the layer with the reduced temperature at the system's walls was different. At higher flow velocities, the lowered temperature zones near the borders were much thinner. However, it could be noticed that even in the case of the lowest mass flow rate, the injection area was located in a field of uniform temperature. The only place of significant temperature heterogeneity in the way of the UWS stream was the injector mounting area, through which the injected UWS passed at the very beginning of the injection process. In that regime, only ligaments are observed [6], which are expected to be weakly sensitive to this temperature drop. The temperature distribution in the cross section was depicted in Figs 12 and 13.

As in the case of the velocity distribution, to verify the temperature homogeneity, the temperature uniformity index was introduced. It was defined using the following formula (Eq. 2).

$$
\mathrm{UI}_{\text {temp }}=1-\frac{\sum\left|\mathrm{T}_{\mathrm{i}}-\mathrm{T}_{\mathrm{avg}}\right| \cdot \mathrm{A}_{\mathrm{i}}}{2 \cdot \mathrm{T}_{\mathrm{avg}} \cdot \sum \mathrm{A}_{\mathrm{i}}}
$$

where: $A_{i}$ was a surface area of a given mesh element; $T_{\text {avg }}$ was the average temperature value; and $T_{i}$ was the actual temperature in the corresponding mesh element.

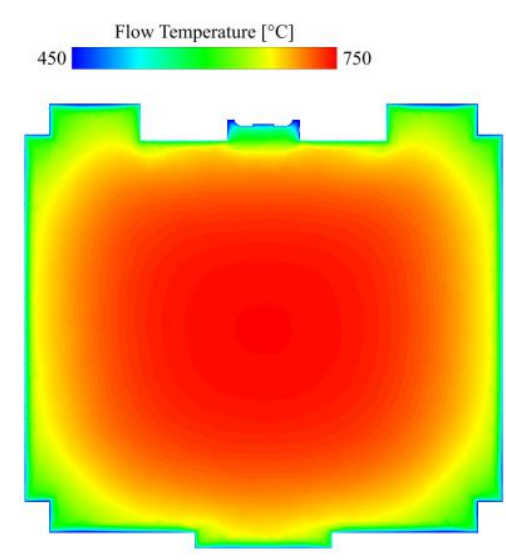

Fig. 12. Temperature distribution at $750^{\circ} \mathrm{C}$ flow temperature and $150 \mathrm{~kg} / \mathrm{h}$ flow rate in the injection plane cross section

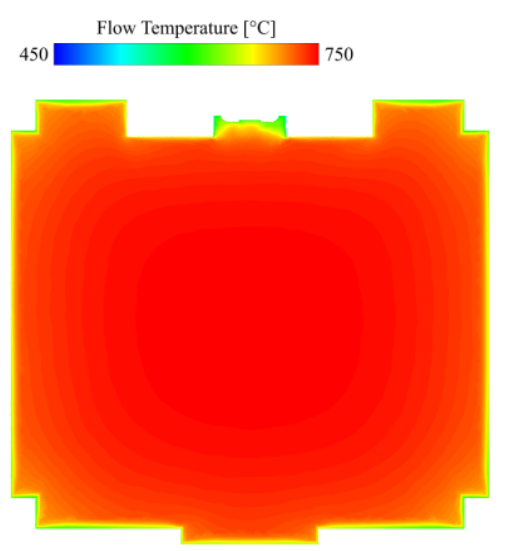

Fig. 13. Temperature distribution at $750^{\circ} \mathrm{C}$ flow temperature and $750 \mathrm{~kg} / \mathrm{h}$ flow rate in the injection plane cross section

The results obtained ranged from $97.42 \%$ to $99.51 \%$, which indicated a high degree of uniformity. The temperature tended to be distributed more evenly at lower flow temperatures. Collected data confirmed the visual observation of an increase in uniformity with increasing air mass flow. The results of the temperature uniformity index, depending on the flow temperature and mass flow rate changes, are depicted in Figs 14 and 15.

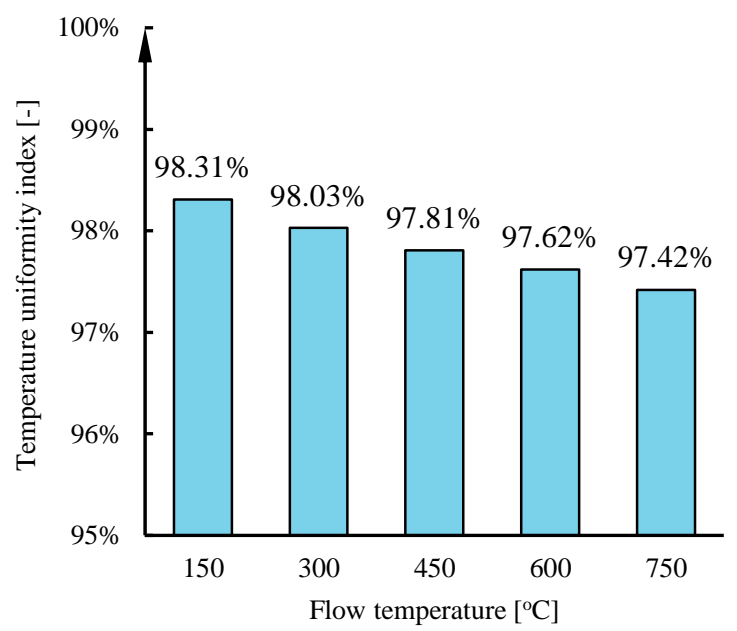

Fig. 14. Temperature uniformity index for the mass flow rate of $150 \mathrm{~kg} / \mathrm{h}$ 


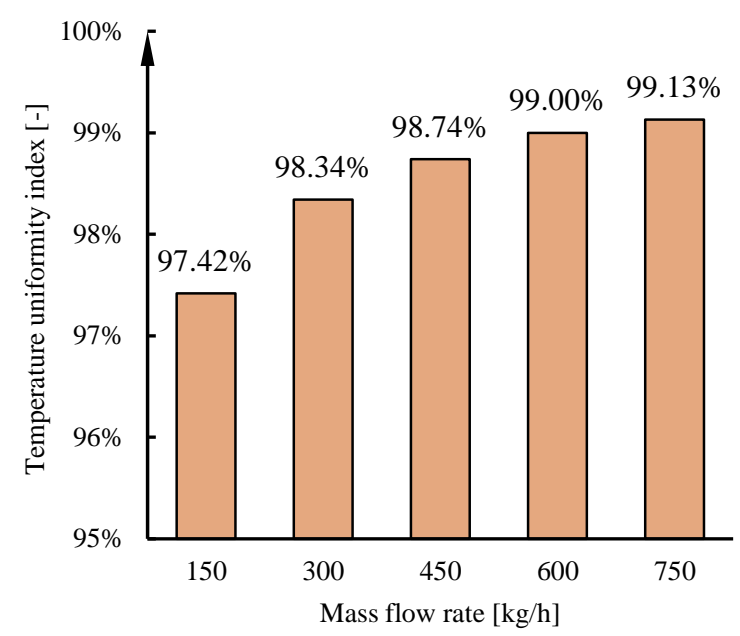

Fig. 15. Temperature uniformity index for the flow temperature of $750^{\circ} \mathrm{C}$

The correctness of the thermocouple placement was verified. In Figs 16 and 17, the temperature distribution in the cross-sectional plane located in the thermocouple's axis was shown for both the case with the slowest flow (mass flow rate $150 \mathrm{~kg} / \mathrm{h}$, in a flow temperature $150^{\circ} \mathrm{C}$ ) and the case with the fastest flow (mass flow rate $750 \mathrm{~kg} / \mathrm{h}$, temperature $750^{\circ} \mathrm{C}$ ). In Figure 16, a thick boundary layer of lowered temperature is visible. Even in this case, the thermocouple's tip is located in an area of uniform temperature.

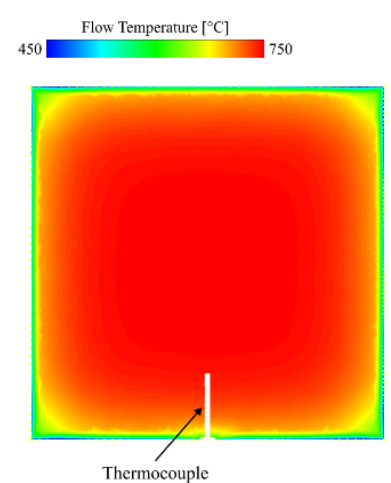

Fig. 16. Temperature distribution at $750^{\circ} \mathrm{C}$ flow temperature and $150 \mathrm{~kg} / \mathrm{h}$ flow rate in the thermocouple plane's cross section

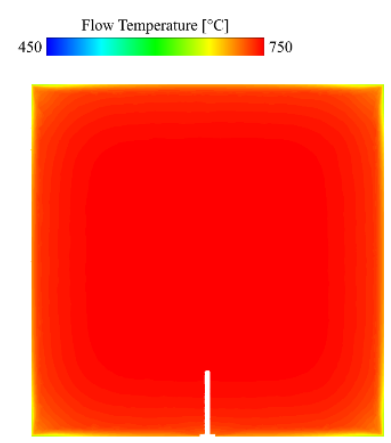

Fig. 17. Temperature distribution at $750^{\circ} \mathrm{C}$ flow temperature and $750 \mathrm{~kg} / \mathrm{h}$ flow rate in the thermocouple plane's cross section

In order to verify the location of the temperature sensor precisely, the temperature values at the tip of the thermo- couple were compared with the flow temperature along the injection axis. Figures of the temperature profiles compared with the temperature values registered on the thermocouple's tip are shown in Fig. 18.

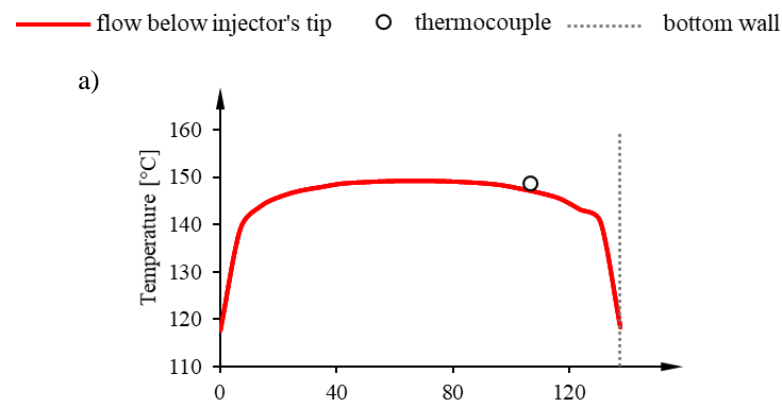

b)

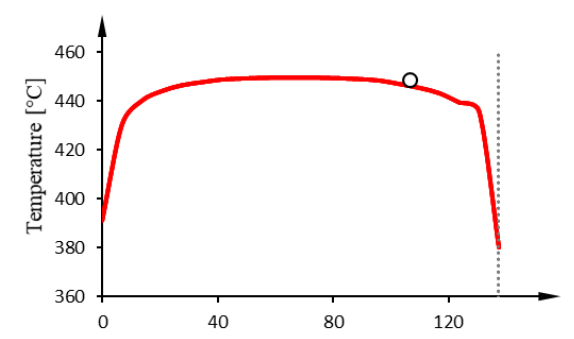

c)

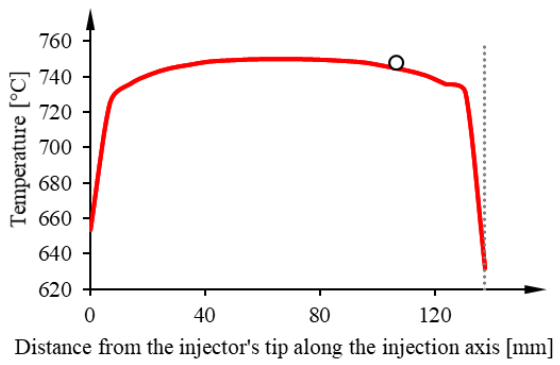

Fig. 18. Comparison of the temperature at the thermocouple's tip and at the injection axis for the following conditions: a) flow temperature $150^{\circ} \mathrm{C}$, mass flow rate $150 \mathrm{~kg} / \mathrm{h}$, b) flow temperature $450^{\circ} \mathrm{C}$, mass flow rate $450 \mathrm{~kg} / \mathrm{h}, \mathrm{c}$ ) flow temperature $750^{\circ} \mathrm{C}$, mass flow rate $750 \mathrm{~kg} / \mathrm{h}$

The graphs obtained indicated that the temperature was almost the same at the thermocouple's tip as in the central part of the injector's axis plane. This region accounted for the majority of the cross-sectional area and was the most important for spray analysis. Significant temperature drops were present in the vicinity of the system walls, but they were located mainly outside the considered spray analysis area.

The conducted simulations indicated that the temperatures measured by the thermocouple in the actual flow rig would be close to the temperatures in the spray area. Combined with the slight disturbance of the flow generated by the thermocouple, tests confirmed its correct positioning.

\subsection{Spray injection}

To verify the suitability of the flow rig for testing UWS injections, simulations of the injection process were carried out. In the simulations, single injections of UWS were considered for the previously discussed operating conditions. Both subcooled and superheated liquid injections were analysed. 
The appearance of the injection process varied between the cases, with significant differences being visible between the subcooled and superheated injections, mass flows rates and temperatures. The superheated spray had a more substantial droplet dispersion, with their diameters being smaller. The subcooled spray had a greater tendency to remain inside the injection core.

In the case of high mass flow rates, the droplets dragged by the flow were also present for the subcooled injection. The smaller droplets had a greater tendency to be dragged by the flow, as illustrated in Figs 19 and 20. Due to the reduced diameters of the droplets in the case of the superheated liquid injection, the entire spray was curved towards the flow direction (Fig. 20). In the case of a subcooled spray, the smaller droplets detached from the main stream and then were blown away with the flow (Fig. 19).

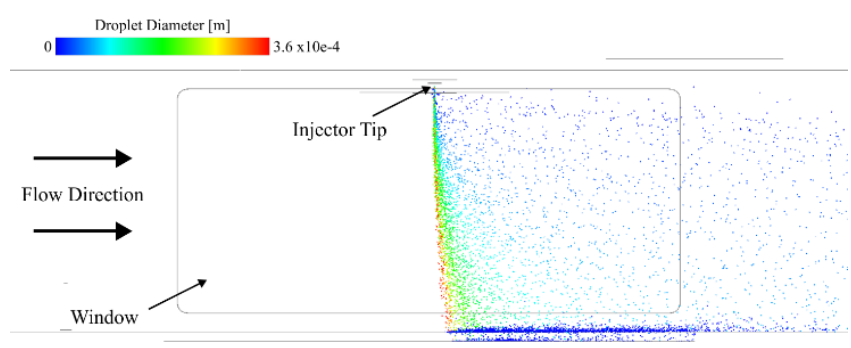

Fig. 19. Side view of the spray cloud for the UWS temperature of $83^{\circ} \mathrm{C}$, flow temperature of $750^{\circ} \mathrm{C}$ and mass flow rate $750 \mathrm{~kg} / \mathrm{h}$

Droplet Diameter $[\mathrm{m}]$

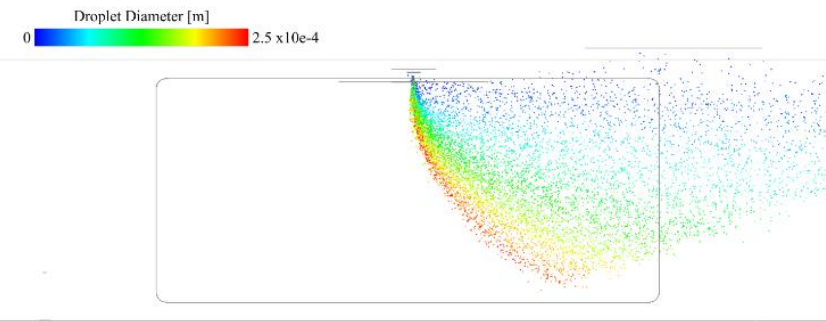

Fig. 20. Side view of the spray cloud for the UWS temperature of $143^{\circ} \mathrm{C}$, flow temperature of $750^{\circ} \mathrm{C}$ and mass flow rate $750 \mathrm{~kg} / \mathrm{h}$

For the lower mass flow rates, this effect occurred to a lesser extent. The detachment of smaller droplets from the main flow was still noticeable, however, the tendency of the spray drift was reduced.

The appearance of the spray was also dependent on the flow temperature. Increasing the temperature resulted in a rise in the gas velocity while reducing its density. The higher temperature could also result in faster evaporation of the injected droplets. In the case of higher-temperature flows, a greater proportion of the droplets was dragged by the transverse flow than in the case of lower temperatures.

For each of these cases, despite the variable nature of the injection, the device provided adequate visibility of the spray in the area of the intended optical access.

In the case of subcooled liquid injection, the droplets tended to splash on the bottom wall. In the case of the lowest mass flow rate, some of the droplets rebounded upstream (Fig. 21). These droplets later began to travel in the direction of the flow. This phenomenon might cause these droplets to be re-registered at the images and thus interfere with the results of the spray observation. A similar phenomenon was observed by Postrioti et al. [15]. The solution to the ambiguity of the results in such a case might be to limit the injection analysis time until the droplet splashing occurs.

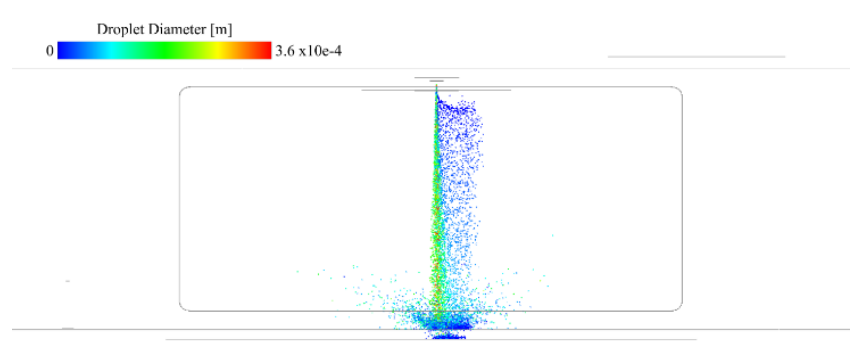

Fig. 21. Side view of the spray cloud for the UWS temperature $83^{\circ} \mathrm{C}$, flow temperature $150^{\circ} \mathrm{C}$ and mass flow rate $150 \mathrm{~kg} / \mathrm{h}$. Some parts of the spray are travelling upstream after rebounding from the bottom wall

For low mass flow rates, vortices were observed near the injector's tip (Fig. 22). The swirl was intensified by the air entraining from the injector mounting area into the injected spray. The resulting vortex affected the trajectory of the small droplets in the upper part of the flow section. The occurrence of this phenomenon shall be linked entirely to the mounting method of the considered injector.

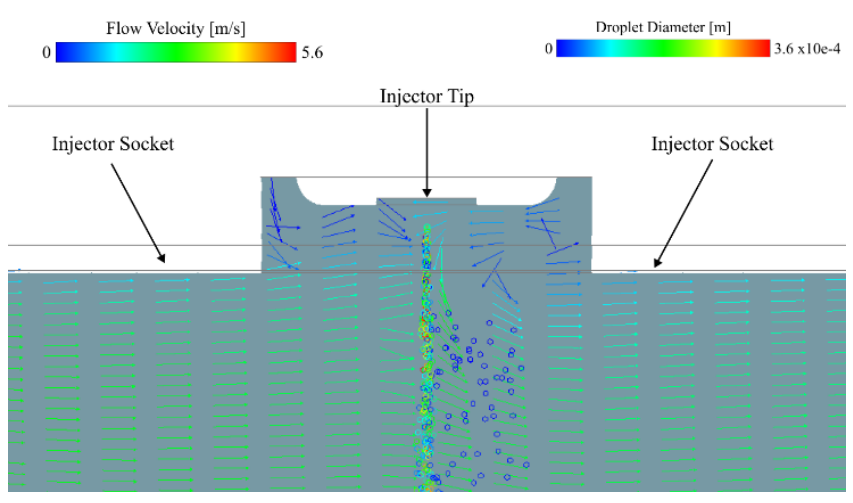

Fig. 22. Side view of the spray cloud and velocity vectors near the injector for the UWS temperature of $83^{\circ} \mathrm{C}$, flow temperature of $750^{\circ} \mathrm{C}$ and mass flow rate $150 \mathrm{~kg} / \mathrm{h}$. Bending of the velocity vectors by the UWS stream in the injector mounting area is visible

To verify the possibility of a secondary breakup of the droplets induced by interaction with the crossflow, it was decided to determine the Weber number (Eq. (3)).

$$
\mathrm{We}=\frac{\varrho \cdot \mathrm{v}^{2} \cdot \mathrm{D}_{32}}{\sigma}
$$

where: We was the Weber number; $\varrho$ was the density of the UWS in the considered temperature; $D_{32}$ was the Sauter mean diameter; and $\sigma$ was the surface tension.

Due to the difficulties in determining the surface tension of the droplets in the superheated liquid, the Weber number was determined only for a UWS of $83^{\circ} \mathrm{C}$. The obtained value of 1.84 indicated that in this case, the secondary breakup of the droplets was not expected to occur.

In the case of the superheated spray, although the surface tension value was reduced, the droplet diameters were significantly reduced. Consequently, the Weber number 
would be even lower than in the case of a subcooled spray; thus, the secondary breakup of the droplets is also not expected in this case.

\section{Summary and conclusions}

Compliance with progressive vehicle emission standards implies the constant development of SCR spray systems. Most spray measurements are carried out in static environments. However, to completely understand sprayrelevant phenomena and verify UWS systems or validate the data from CFD modelling, measurements in crossflow conditions are necessary. Meeting the abovementioned requirements is mainly realised in crossflow test rigs.

The design of the flow rig was presented and numerically tested to confirm its usability for optical measurements of UWS sprays in exhaust system-relevant conditions. The aim was to verify its broad range of applications and the appropriate location of the thermocouple to avoid its impact on the flow. The following conclusions were drawn:

- The flow rig was adaptable to the wide range of operating conditions, including the conditions present in lowduty diesel engines.

- The nature of the velocity field in the spray area remained the same in all the cases. The flow was characterised by minor vortices near the nozzle, however, their influence on the spray formation was irrelevant. The velocity uniformity index measured in the cross-sectional plane in the injector axis exceeded the value of $95 \%$ in all the cases.

- Temperature distribution was characterised by slight variations. Its nature remained similar for most cases. However, an increased gas mass flow rate resulted in a more uniform temperature distribution. The temperature uniformity index measured in the cross-sectional plane in the injector axis ranged from $97.4 \%$ to over $99 \%$, depending on the considered case.

- The impact of the thermocouple on the flow was found to be negligible in terms of the spray measurements, regardless of the flow conditions or type of injection.
- The thermocouple was placed in the highest temperature region and was not affected by the thermal boundary layer.

- Major parts of the spray clouds were well separated from the side windows. This occurred for all the mass flow rates and flow temperatures.

- The application of a gas mass flow rate of $150 \mathrm{~kg} / \mathrm{h}$ resulted in minor interactions of the droplets with the flow; therefore some of the entrained droplets moved upstream.

- The superheated spray cloud was highly prone to drift due to the interactions of the droplets with the crossflow. The higher the gas flow velocity, the more deflected the streamlines of the smaller droplets.

- In none of the cases would the droplets undergo a secondary breakup.

In view of the above, the presented flow rig is presumed to fulfil all expectations and allow reliable spray examinations in crossflow conditions, which are more relevant to the prevailing industrial applications. Such tests are expected to have a significant impact on the development of SCR systems. The presence of the crossflow was found to have a profound effect on the spray observations and measurements. Nonetheless, the flow rig was characterised by a very uniform velocity field and temperature distribution in the spray zone.

\section{Acknowledgements}

The project leading to this application has received funding from the National Centre for Research and Development (NCBiR), grant no. MAZOWSZE/0101/19-00, programme Ścieżka dla Mazowsza, project budget: 9880490.25 PLN.

Numerical simulations were performed using AVL FIRETM software under AVL University Partnership Program.

\section{Nomenclature}

$\mathrm{A}_{\mathrm{i}} \quad$ the surface of a given (i-th) mesh element

CFD computational fluid dynamics

DDM discrete droplet model

$\mathrm{NO}_{\mathrm{x}} \quad$ nitrogen oxides

RANS Reynolds-averaged Navier-Stokes

SCR selective catalytic reduction

$\mathrm{T}_{\mathrm{i}} \quad$ mean temperature in a given (i-th) mesh element
$\mathrm{T}_{\mathrm{avg}}$ the average temperature in the cross-sectional area

$\mathrm{UI}_{\text {temp }}$ temperature uniformity index

$\mathrm{UI}_{\mathrm{vel}}$ velocity uniformity index

UWS urea-water solution

$\mathrm{V}_{\mathrm{i}} \quad$ mean velocity in a given (i-th) mesh element

$\mathrm{V}_{\text {avg }}$ the average velocity in the cross-sectional area

\section{Bibliography}

[1] ADITYA WARDANA, M.K., HYUN, J., LIM, O. A study of urea injection timing to predict the $\mathrm{NO}_{\mathrm{x}}$ conversion in SCR systems. Energy Procedia. 2019, 158, 1942-1948. https://doi.org/10.1016/j.egypro.2019.01.449

[2] BORUC, Ł., ROGOZ, R., BACHANEK, J. et al. An experimental facility for rapid testing of SCR systems. SAE Technical Paper 2020-01-2192. 2020.

https://doi.org/10.4271/2020-01-2192

[3] BOULET, P., TISSOT, J., TRINQUET, F. et al. Enhancement of heat exchanges on a condenser using an air flow containing water droplets. Applied Thermal Engineering. 2013, 50(1), 1164-1173.

https://doi.org/10.1016/j.applthermaleng.2012.08.039

[4] BRIZI, G., POSTRIOTI, L., VAN VUUREN, N. Experimental analysis of SCR spray evolution and sizing in hightemperature and flash boiling conditions. SAE International Journal of Fuels and Lubricants. 2019, 12(2), 4-12. https://doi.org/10.4271/04-12-02-0006

[5] KAPUSTA, Ł.J., ROGOZ, R., BACHANEK, J. Experimental and numerical study to evaluate the effect of flash 
boiling on urea-water solution sprays and selective catalytic reduction system performance. Atomisation and Sprays. 2021, 31(5), 89-117.

https://doi.org/10.1615/AtomizSpr.2021035461

[6] KAPUSTA, Ł.J., SUTKOWSKI, M., ROGÓŻ, R. et al. Characteristics of water and urea-water solution sprays. $\mathrm{Ca}$ talysts. 2019, 9(9). 750.

https://doi.org/10.3390/catal9090750

[7] LIAO, Y., DIMOPOULOS EGGENSCHWILER, P., SPITERI, A. et al. Fluid dynamic comparison of AdBlue injectors for SCR applications. SAE International Journal of Engines. 2015, 8(5), 2303-2311.

https://doi.org/10.4271/2015-24-2502

[8] LIEBER, C., KOCH, R., BAUER, H.-J. Microscopic imaging spray diagnostics under high temperature conditions: application to urea-water sprays. Applied Sciences. 2019, 9(20), 4403. https://doi.org/10.3390/app9204403

[9] LIEBER, C., KOCH, R., BAUER, H.-J. Spray evaporation of urea-water solution: experiments and modelling. Experimental Thermal and Fluid Science. 2020, 116, 110108. https://doi.org/10.1016/j.expthermflusci.2020.110108

[10] NISHAD, K., RIES, F., JANICKA, J. et al. Analysis of spray dynamics of urea-water-solution jets in a SCRDeNOx system: an LES based study. International Journal of Heat and Fluid Flow. 2018, 70, 247-258.

https://doi.org/10.1016/j.ijheatfluidflow.2018.02.017

[11] NOCIVELLI, L., MONTENEGRO, G., DIMOPOULOS EGGENSCHWILER, P. Low pressure-driven injection characterization for SCR applications. SAE Technical Paper 2019-01-0994. 2019. https://doi.org/10.4271/2019-01-0994

[12] PAYRI, R., BRACHO, G., GIMENO, J. et al. Spray characterization of the urea-water solution (UWS) injected in a hot air stream analogous to SCR system operating conditions. SAE Technical Paper 2019-01-0738. 2019. https://doi.org/10.4271/2019-01-0738

[13] PAYRI, R., BRACHO, G., GIMENO, J. et al. Investigation of the urea-water solution atomisation process in engine exhaust-like conditions. Experimental Thermal and Fluid Science. 2019, 108, 75-84.

https://doi.org/10.1016/j.expthermflusci.2019.05.019
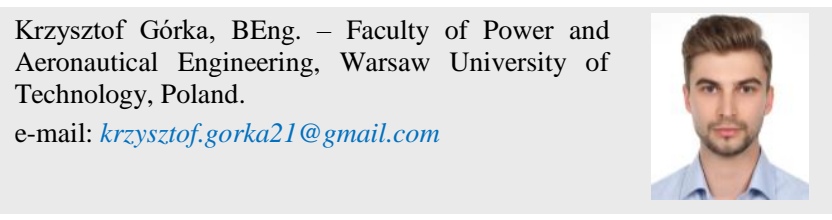

Łukasz Jan Kapusta. DEng. - Faculty of Power and Aeronautical Engineering, Warsaw University of Technology, Poland.

e-mail: lukasz.kapusta@pw.edu.pl
[14] PAYRI, R., BRACHO, G., MARTÍ-ALDARAVÍ, P. et al. Computational study of urea-water solution sprays for the analysis of the injection process in SCR-like conditions. Industrial \& Engineering Chemistry Research. 2020, 59(41), 18659-18673.

https://doi.org/10.1021/acs.iecr.0c02494

[15] POSTRIOTI, L., BRIZI, G., FINORI, G.M. Experimental analysis of water pressure and temperature influence on atomization and evolution of a port water injection spray. Applied Sciences. 2021, 11(13), 5980. https://doi.org/10.3390/app11135980

[16] SCHMIDT, A., VAN DER KLEY, S., WAGNER, S. Optically accessible generic exhaust gas test bench for the investigation of fundamental SCR-relevant processes. Applied Optics. 2020, 59(23), 6953-6958. https://doi.org/10.1364/AO.397574

[17] SPITERI, A., DIMOPOULOS EGGENSCHWILER, P. Experimental fluid dynamic investigation of urea-water sprays for diesel selective catalytic reduction-DeNOx applications. Industrial \& Engineering Chemistry Research. 2014, 53(8), 3047-3055. https://doi.org/10.1021/ie404037h

[18] SPITERI, A., DIMOPOULOS EGGENSCHWILER, P., LIAO, Y. et al. Comparative analysis on the performance of pressure and air-assisted urea injection for selective catalytic reduction of $\mathrm{NO}_{\mathrm{x}}$. Fuel. 2015, 161, 269-277.

https://doi.org/10.1016/j.fuel.2015.08.061

[19] VARNA, A., BOUlOUCHOS, K., SPITERI, A. et al. Numerical modelling and experimental characterization of a pressure-assisted multi-stream injector for SCR exhaust gas after-treatment. SAE Technical Paper 2014-01-2822. 2014. https://doi.org/10.4271/2014-01-2822

[20] VARNA, A., SPITERI, A.C., WRIGHT, Y.M. et al. Experimental and numerical assessment of impingement and mixing of urea - water sprays for nitric oxide reduction in diesel exhaust. Applied Energy. 2015, 157, 824-837. https://doi.org/10.1016/j.apenergy.2015.03.015
Bartosz Kaźmierski, BEng. - Faculty of Power and Aeronautical Engineering, Warsaw University of Technology, Poland.

e-mail: bartosz.kazmierskil@gmail.com 